\title{
Expression of mef2 Genes in the Mouse Central Nervous System Suggests a Role in Neuronal Maturation
}

\author{
Gary E. Lyons, ${ }^{1}$ Bruce K. Micales, ${ }^{1}$ John Schwarz, ${ }^{2}$ James F. Martin, ${ }^{2}$ and Eric N. Olson ${ }^{2}$ \\ 'Department of Anatomy, The University of Wisconsin Medical School, Madison, Wisconsin 53706 and \\ ${ }^{2}$ Department of Biochemistry and Molecular Biology, The University of Texas M. D. Anderson Cancer Center, \\ Houston, Texas 77030
}

\begin{abstract}
Members of the myocyte enhancer factor 2 (MEF2) gene family are expressed in a dynamic pattern during development of the CNS of pre- and postnatal mice. The four MEF2 genes, Mef2A, $-B,-C$, $-D$, encode transcription factors belonging to the MADS (MCM1-agamous-deficiens-serum response factor) superfamily of DNA binding proteins. MEF2 factors have previously been shown to be positive regulators of gene expression in terminally differentiated muscle cells. To begin to determine the role of MEF2 factors in CNS development, we used in situ hybridization with gene-specific CRNA probes to define the expression patterns of each of the four Mef2 mRNAs in the developing and mature mouse CNS. Mef2C mRNA was first detected in a ventral portion of the telencephalon at $11.5 \mathrm{~d}$ postcoltum (p.c.). By 13.5 d p.c., each of the four Mef2 genes were expressed in overlapping yet distinct patterns in regions of the frontal cortex, midbrain, thalamus, hippocampus, and hindbrain. Temporal and spatial patterns of embryonic Mef2 gene expression appeared to follow gradients of neuron maturation and suggested that the onset of Mef2 gene expression coincides with withdrawal from the cell cycle and initiation of neuronal differentiation. This correlation is particularly striking for Purkinje cells in the cerebellum. Since the molecular mechanisms that regulate neuron differentiation are unknown, we propose that the MEF2 factors are likely to play an important role in this process.

[Key words: Mef2 mRNAs, transcription factor genes, mouse embryo, postnatal brain, in situ hybridization, neuron maturation]
\end{abstract}

In the mouse, the Myocyte Enhancer Factor 2 genes, Mef2A, $-B$, and $-D$ are expressed in a wide range of adult tissues, whereas $M e f 2 C$ expression appears to be restricted to brain, skeletal muscle, and spleen (Martin et al., 1993; McDermott et al., 1993). Our preliminary in situ hybridization results indicate that each of the four members of the Mef2 gene family is expressed in the embryonic mouse brain by $13.5 \mathrm{~d}$ postcoitum (p.c.; Ed-

\footnotetext{
Jan. 19, 1995; revised March 30, 1995; accepted April 6, 1995.

G.E.L. thanks Dr. Steve Kornguth and Dr. Tom Sutula for helpful comments on the manuscript. This research was supported by grants from the Muscular Dystrophy Association and the NIH (HD29471) to G.E.L.; E.N.O. was supported by grants from the NIH, Muscular Dystrophy Association and the Robert A. Welch Foundation.

Correspondence should be addressed to Gary E. Lyons, Department of Anatomy, University of Wisconsin Medical School, 1300 University Avenue, Madison, WI 53706.

Copyright (C) 1995 Society for Neuroscience $0270-6474 / 95 / 155727-12 \$ 05.00 / 0$
}

mondson et al., 1994). One other published in situ hybridization result with a $M E F 2$ probe shows that $M E F 2 C$ is detectable in several neuronal layers of the frontal cortex in 1 week and 4 week postnatal rat brains (Leifer et al., 1993).

The MEF2 proteins were originally identified as a musclespecific DNA binding activity in nuclear extracts that recognized a conserved $\mathrm{A} / \mathrm{T}$-rich sequence associated with numerous muscle-specific genes (Gossett et al., 1989; Cserjesi and Olson, 1991). The cloning of MEF2 showed it is encoded by four vertebrate genes, $M e f 2 A,-B,-C$, and $-D$, whose products belong to the MADS (MCM1, agamous, deficiens, serum response factor) family of transcription factors (Chambers et al., 1992; Pollock and Treisman, 1992; Yu et al., 1992; Breitbart et al., 1993; Leifer et al., 1993; Martin et al., 1993, 1994; McDermott et al., 1993). The four $M E F 2$ gene products are highly homologous within the MADS domain, which mediates dimerization and DNA binding to the consensus sequence $\mathrm{CTA}(\mathrm{A} / \mathrm{T})_{4} \mathrm{TAG} / \mathrm{A}$, but they are divergent in their carboxyl-termini. Additional complexity of this family of regulators arises from alternative splicing of Mef 2 transcripts, yielding isoforms with common DNA binding domains, but unique carboxyl-termini (Yu et al., 1992; Martin et al. 1993, 1994).

Recently, several laboratories have focused on the role of the $M e f 2$ genes in skeletal and cardiac muscle development in vitro and in vivo (Cserjesi and Olson, 1991; Chambers et al., 1992; Edmondson et al., 1992; Navankasattusas et al., 1992; Yu et al., 1992; Breitbart et al., 1993; Cheng et al., 1993; Martin et al., 1993, 1994; McDermott et al., 1993). In skeletal muscle, MEF2 proteins appear to act in concert with the MyoD family of basic helix-loop-helix (bHLH) myogenic factors to regulate musclespecific gene transcription (Edmondson et al., 1992; Cheng et al. 1993; Yee and Rigby, 1993; Kaushal et al., 1994; Leibham et al., 1994).

Like their patterns of expression in muscle, we found that the four $M e f 2$ genes are expressed in spatially and temporally specific patterns during brain development. Our results suggest that, similar to its expression pattern in striated muscle, Mef2 gene expression in the CNS occurs in neurons exiting the cell cycle and entering differentiation. $\Lambda \mathrm{s}$ the CNS develops, we obscrved that patterns of expression of the four Mef2 genes in specific regions of the mouse brain followed gradients of neuronal maturation. Since these patterns correlate with published data on brain-specific gene expression, this study may also serve to identify potential target genes that the MEF2 proteins regulate. Since the molecular mechanisms that regulate neuron differentiation are unknown, we propose that the MEF2 factors are likely to play an important role in this process. 

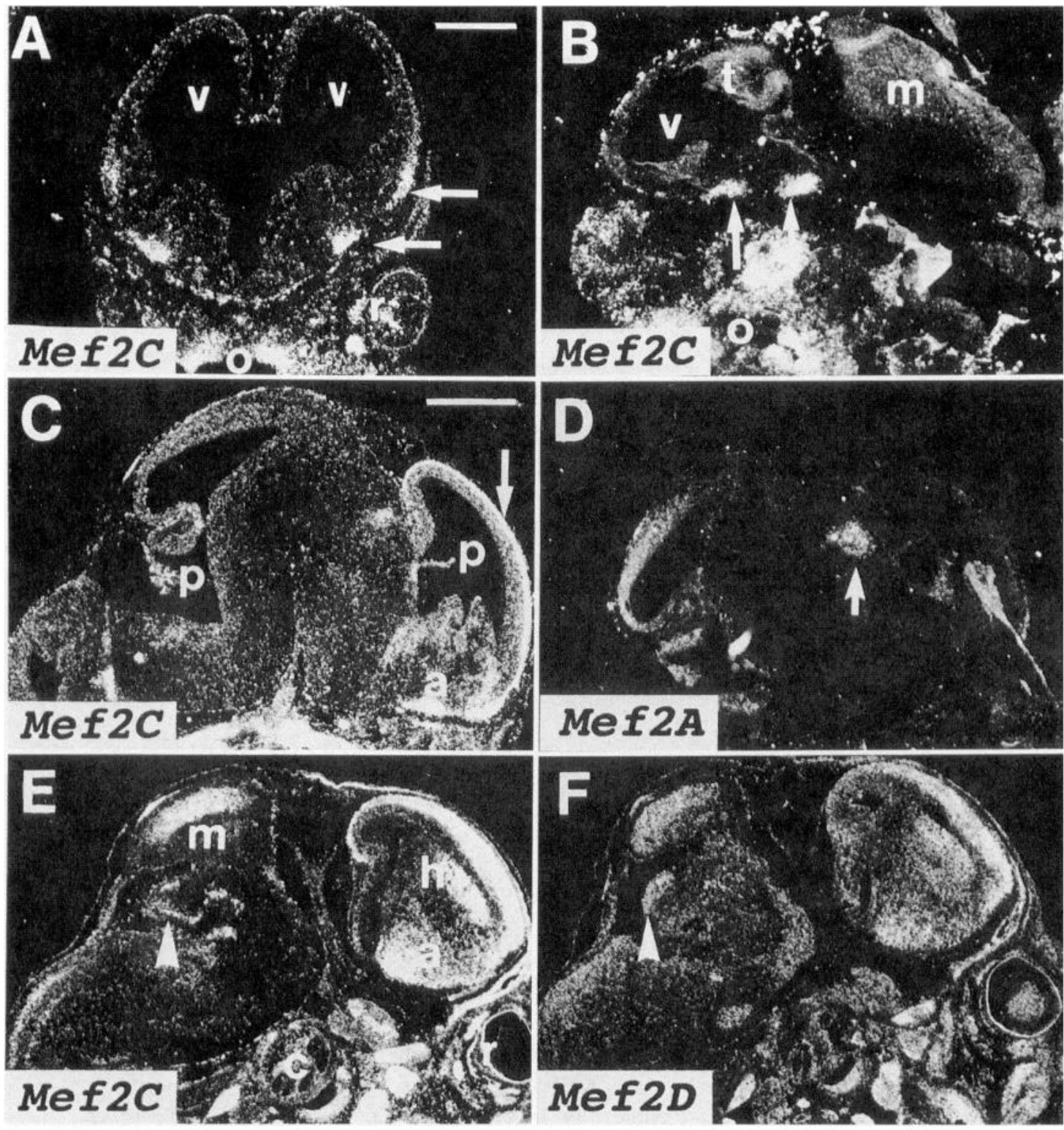

Figure 1. Mef2 gene expression in the mouse brain from 11.5 to $14.5 \mathrm{~d}$ p.c. The dark-field micrograph in $A$ shows a frontal section through the brain of an $11.5 \mathrm{~d}$ embryo passing through two ventricles $(v)$. B. A parasagittal section through the head of a second $11.5 \mathrm{~d}$ embryo showing the same Mef $2 C$ expression (arrows in $A$ and $B$ ) in the telencephalon $(t)$. Grains are also detected over neural crest cells in the maxilla $(o)$ in $A$ and $B$. The dark-field micrographs in $C$ and $D$ represent two consecutive parasagittal sections of $13.5 \mathrm{~d}$ embryos that were hybridized to probes for $(C)$ $M e f 2 C$ and $(D) M e f 2 A$. (Arrow in $C$ points to the frontal cortex. Arrow in $D$ points to the developing thalamus.) $E$ and $F$, Dark-field micrographs of parasagittal sections of $14.5 \mathrm{~d}$ p.c. embryos that were hybridized with probes for $(E) \operatorname{Mef} 2 C,(F) \operatorname{Mef} 2 D$. Arrowheads in E and F point to layers of the cerebellum. $a$, amygdala; $c$, cochlea; $h$, hippocampus; $m$, midbrain; $p$, choroid plexus; $r$, retina. Scale bar: $A-B, 400 \mu \mathrm{m} ; C-F, 800 \mu \mathrm{m}$.

\section{Materials and Methods}

Preparation and prehybridization of tissue sections. The protocol that was used to fix and embed BALB/c and C57BL/6 $\times$ DBA $/ 2$ embryos, fetuses, and postnatal brains is described in detail in Lyons et al. (1990). Briefly, embryos were fixed in $4 \%$ paraformaldehyde in phosphate-buffered saline (PBS) overnight, dehydrated, and infiltrated with paraffin. Serial sections $(5-7 \mu \mathrm{m})$ were mounted on gelatinized slides. One to three sections were mounted/slide, deparaffinized in xylene, rehydrated, and postfixed. The sections were digested with proteinase $\mathrm{K}$, postfixed, treated with triethanolamine/acetic anhydride, washed, and dehydrated.

$c R N A$ probe preparation. In order to distinguish between transcripts within the $M E F 2$ multigene family, we used probes derived from the 3 ' coding and noncoding regions of the mRNAs that are not conserved between the different genes. cDNAs were subcloned into the vector, Bluescript (Stratagene). The following probes were used. (1) Mef $2 \mathrm{~A}$ : 388 base pair mouse cDNA (Edmondson et al., 1994) in pAMP1 (GIB-
CO-BRL) was linearized with NotI and transcribed with T7 polymerase for the antisense cRNA probe. The plasmid was linearized with SalI and transcribed with Sp6 polymerase for the sense control probe. (2) Mef2B: 156 base pair mouse cDNA (Martin and Olson, manuscript in preparation) in pAMP1 (GIBCO-BRL) was linearized with NotI and transcribed with $\mathrm{T} 7$ polymerase for the antisense probe. The plasmid was linearized with EcoRI and transcribed with Sp6 for the sense control probe. (3) Mef2C: 374 base pair mouse cDNA (Edmondson et al., 1994) in pBSKII (Stratagene) was linearized with HindIII and transcribed with T3 polymerase for the antisense cRNA probe. The plasmid was linearized with BglI and transcribed with $\mathrm{T} 7$ polymerase for the sense control probe. (4) Mef2D: 715 base pair mouse cDNA (Edmondson et al., 1994) in pBSKII (Stratagene) was linearized with NotI and transcribed with T7 polymerase for the antisense cRNA probe. The plasmid was linearized with EcoRI and transcribed with T3 polymerase for the sense control probe. 

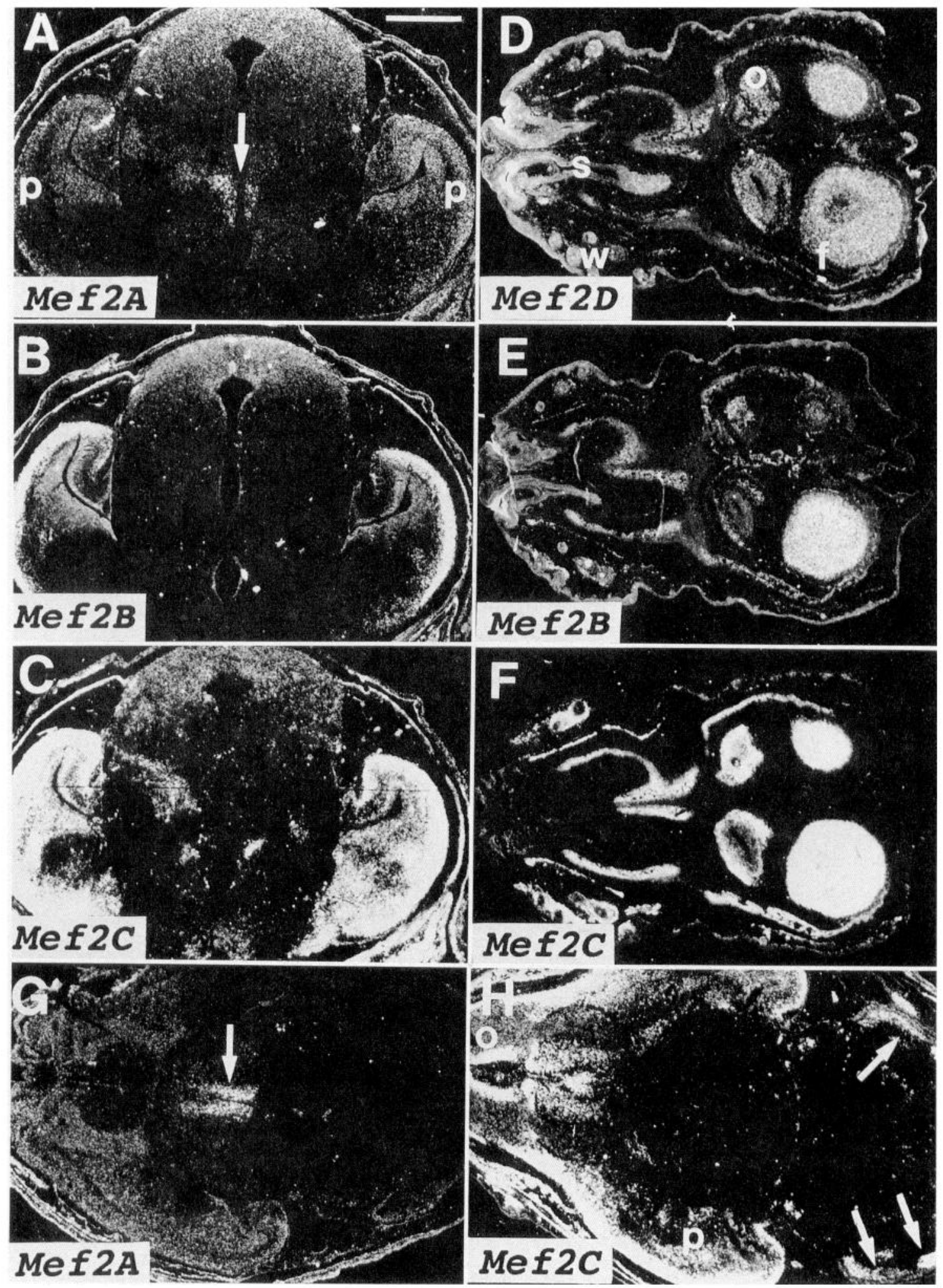

Figure 2. Transverse and frontal sections of 15.5-16.5 d p.c. mouse brains show the anteroposterior and lateral extents of $M e f 2$ gene expression. Frontal sections close to the midbrain of a $15.5 \mathrm{~d}$ mouse brain were hybridized with probes to Mef $2 A(A),-B(B)$, and $-C(C)$. Frontal sections through the frontal cortex $(f)$, olfactory bulbs $(o)$, and nasal sinus $(s)$ area of a $15.5 \mathrm{~d}$ mouse embryonic head were hybridized with probes to $\operatorname{Mef} 2 D(D),-B(E)$, and $-C(F)$. Transverse sections through a $16.5 \mathrm{~d}$ mouse brain were hybridized with probes to Mef2A $(G)$ and $-C(H)$. Arrows in $A$ and $G$ point to the thalamus. Arrows in $H$ point to the cerebellum. $p$, parietal cortex; $w$, whisker follicle. Scale bars: $A-H$, $800 \mu$ m. 


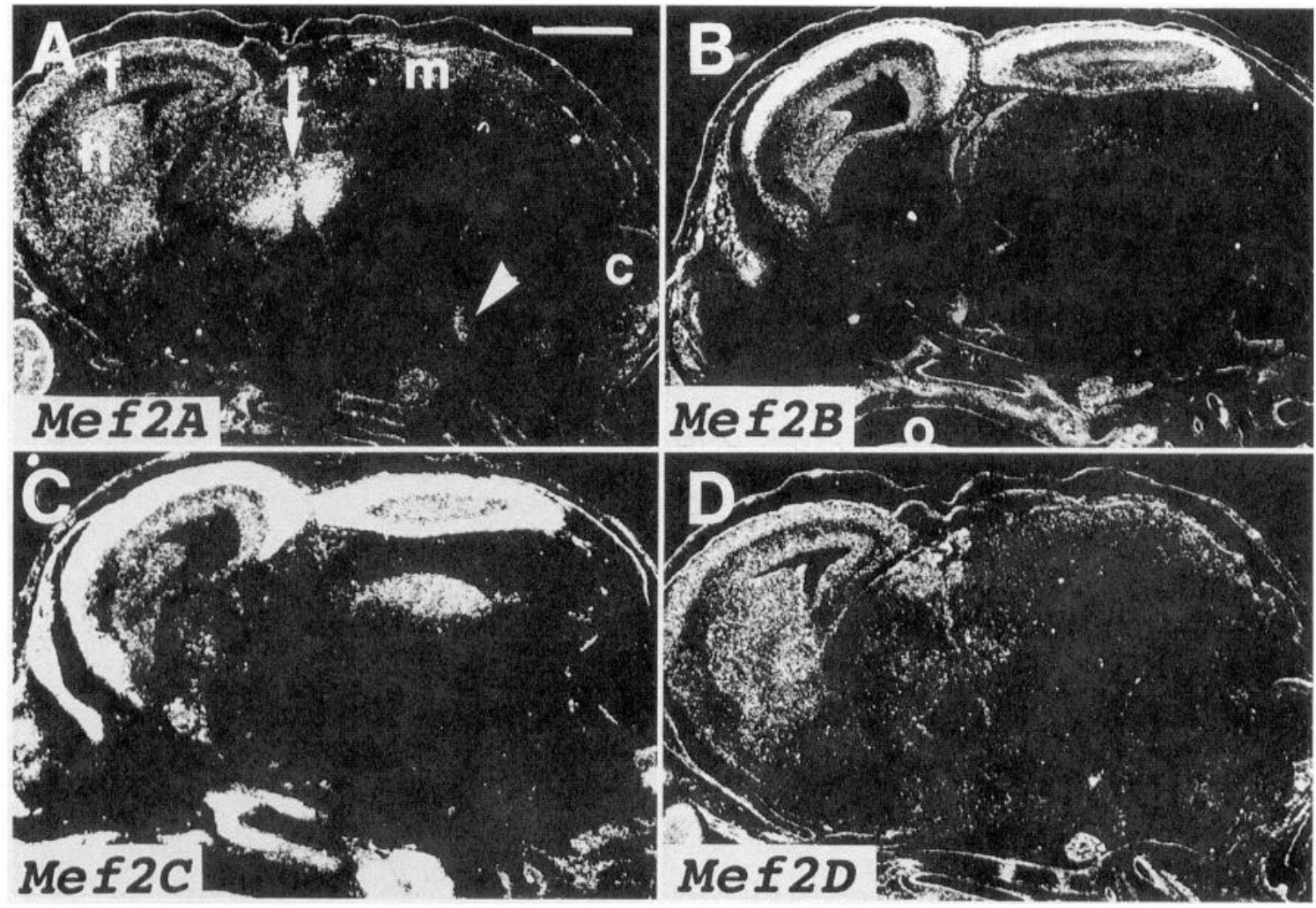

Figure 3. Members of the Mef2 gene family are expressed in overlapping but distinct patterns in the prenatal mouse brain. Dark-field micrographs show parasagittal sections of 16.5 d p.c. embryos that were hybridized with probes for $\operatorname{Mef} 2 A(A), \operatorname{Mef} 2 B(B), \operatorname{Mef} 2 C(C)$, and $M e f 2 D(D)$ mRNAs. Arrow in $A$ indicates the thalamus; arrowhead points to the pontine nuclei. The pigmented layer of the retina $(r)$ in the eye is refractile under darkfield illumination. $c$, cerebellum; $f$, frontal cortex; $h$, hippocampus; $m$, midbrain; $o$, oral cavity. Scale bar: $A-D, 800 \mu \mathrm{m}$.

The cRNA transcripts were synthesized according to manufacturer's conditions (Stratagene) and labeled with ${ }^{35} \mathrm{~S}-\mathrm{UTP}(>1000 \mathrm{Ci} / \mathrm{mmol} ;$ Amersham). cRNA transcripts larger than 100 nucleotides were subjected to alkali hydrolysis to give a mean size of 70 bases for efficient hybridization.

Hybridization and washing procedures. Sections were hybridized overnight at $52^{\circ} \mathrm{C}$ in $50 \%$ deionized formamide, $0.3 \mathrm{M} \mathrm{NaCl}, 20 \mathrm{mM}$ Tris- $\mathrm{HCl} \mathrm{pH} 7.4,5 \mathrm{~mm}$ EDTA, $10 \mathrm{~mm} \mathrm{NaPO}, 10 \%$ dextran sulfate, $1 \times$ Denhardt's, $50 \mu \mathrm{g} / \mathrm{ml}$ total yeast RNA, and $50-75,000 \mathrm{cpm} / \mu \mathrm{l}{ }^{35} \mathrm{~S}$ labeled cRNA probe. The tissue was subjected to stringent washing at $65^{\circ} \mathrm{C}$ in $50 \%$ formamide, $2 \times$ SSC, $10 \mathrm{mM}$ DTT, and washed in PBS before treatment with $20 \mu \mathrm{g} / \mathrm{ml}$ RNase A at $37^{\circ} \mathrm{C}$ for $30 \mathrm{~min}$. Following washes in $2 \times \mathrm{SSC}$ and $0.1 \times \mathrm{SSC}$ for $10 \mathrm{~min}$ at $37^{\circ} \mathrm{C}$, the slides were dehydrated and dipped in Kodak NTB-2 nuclear track emulsion and exposed for 1 week in light-tight boxes with dessicant at $4^{\circ} \mathrm{C}$. Photographic development was carried out in Kodak D-19. Slides were counterstained lightly with Toluidine blue and analyzed using both light- and dark-field optics of a Zeiss Axiophot microscope. Sense control cRNA probes (identical to the mRNAs) always gave background levels of hybridization signal. Several examples of the sense control hybridization results are shown in the figures. Embryonic structures were identified with the help of the following atlases: Rugh (1990), Kaufman (1992), Schambra et al. (1992), and Altman and Bayer (1995).

\section{Results}

Mef 2 gene expression in the embryonic CNS and neural crest In situ hybridization with cRNA probes specific for each of the four $M e f 2$ gene transcripts did not detect any of these mRNAs in ectoderm or neural tissues from 7.5-10.5 d postcoitum (p.c.), with the exception of neural crest cells (Edmondson et al., 1994). Neural crest cells arise from the dorsal portion of the neural tube and migrate to a number of locations to form a variety of cell types including neurons of dorsal root ganglia and sympathetic ganglia, smooth muscle cells, and melanocytes. Mef $2 C$ mRNAs were first detected in the CNS at day 11.5 p.c. within two clusters of cells near the intermediate zone of the preoptic area (Fig. $1 A, B$; Schambra et al., 1992) of the telencephalon. This region of the embryonic brain is one of the first in which neurons begin to differentiate (Altman and Bayer, 1995). Serial sections hybridized with the other $M e f 2$ probes resulted in only background levels of grains at this stage (data not shown).

At 13.5 d p.c., $M e f 2 C$ gene transcripts were expressed in a layer of cells in the intermediate zone of the frontal cortex (Fig. $1 C$; Schambra et al., 1992) and in cells of the olfactory bulb (data not shown). In contrast to this pattern, Mef $2 A$ mRNAs were detected predominantly in the region of the developing thalamus (Fig. $1 D$, arrow). Each of these regions in the developing brain is an area that contains differentiating neurons (Altman and Bayer, 1995). Cells in the choroid plexus were also positive for $M e f 2 C$ expression (Fig. 1C), but this may reflect the presence of some smooth muscle cells in the blood vessels in this structure.

At 13.5 d p.c., Mef2 gene transcripts were also localized in different regions of the neural tube (data not shown). Mef $2 \mathrm{~A}$ mRNAs were distributed in a gradient with highest levels in the dorsal portion of the neural tube and lowest levels in the ventral portion. Mef $2 C$ was expressed in a layer of cells only in the dorsal region. $M e f 2 D$ mRNAs were distributed uniformly throughout the neural tube (data not shown).

Examination of parasagittal sections of 14.5 d p.c. brains revealed that $M e f 2 C$ and - $D$ mRNAs were detected in the embry- 

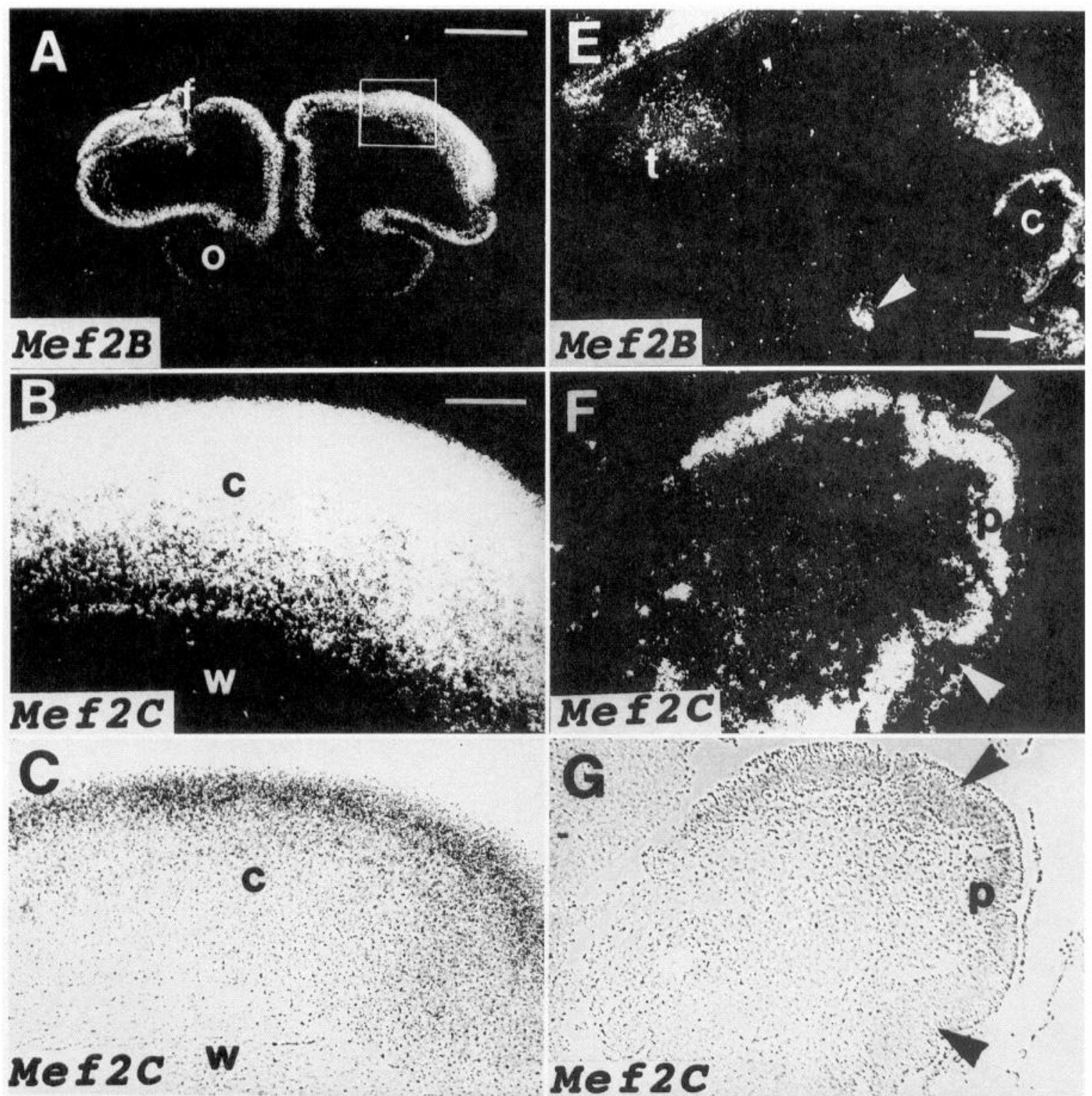

Mef2CW
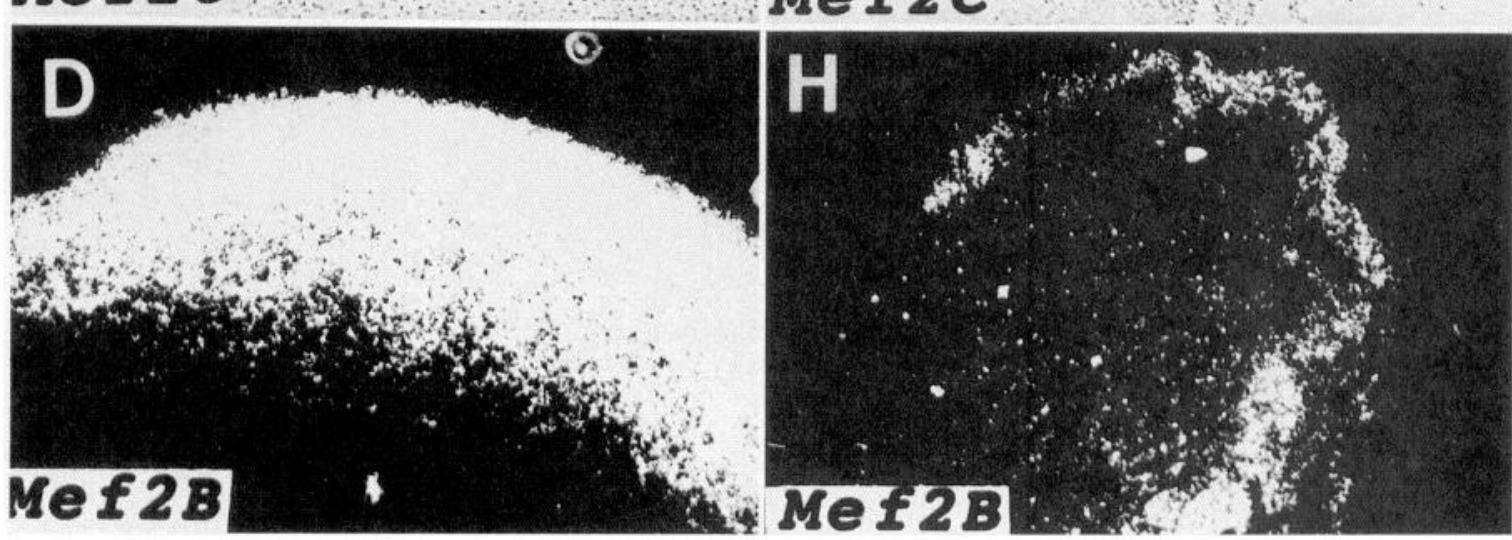

Figure 4. Localization of $M e f 2 B$ and $-C$ gene transcripts in the neonatal mouse brain. $A$, Dark-field image of a frontal section shows that $M e f 2 B$ mRNAs are detected in the layers of the frontal cortex $(f)$ and olfactory bulbs $(o)$. B. Dark-field image; $C$, Phase-contrast image of the cortical region of the area indicated by the box in $A$ from a serial section hybridized with the Mef $2 C$ probe. $D$, Higher magnification of the region enclosed in the box in $A$. Comparison of $B$ and $D$ shows that $M e f 2 C$ is expressed in more cortical layers than $M e f 2 B$. $E$, Parasagittal section of a neonatal brain hybridized with the $M e f 2 B$ probe shows that these transcripts are detected in a region of the inferior colliculus $(i)$, the cerebellum (c), cells in the pontine nuclei (arrowhead), thalamus $(t)$ and a region of the medulla oblongata (arrow). $F$, Dark-field micrographs; $G$, Phase-contrast micrographs of a serial section to that in $E$ hybridized with the Mef $2 C$ probe. $H$, Higher magnification of the cerebellum shown in $E$. Arrowheads in $F$ and $G$ indicate the external granule cell layer outside of the Purkinje cell layer $(p)$, which likely contains a mixture of Purkinje cells and differentiated granule cell neurons. Scale bar: $A$ and $E, 800 \mu \mathrm{m} ; B-D$ and $F-H, 200 \mu \mathrm{m}$. 


\subsection{Day Embryo}
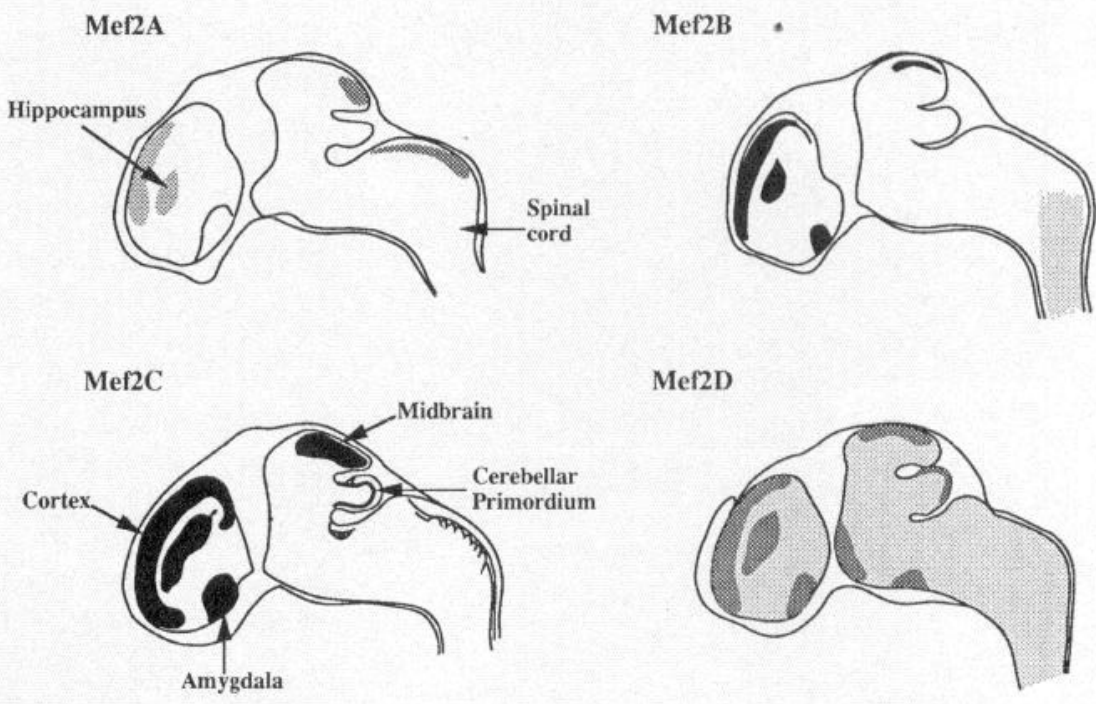

Mef2D

\section{Neonatal Brain}

Mef2A

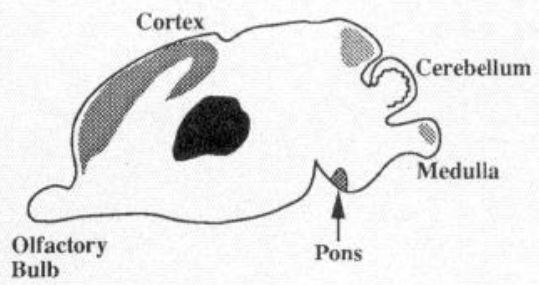

Mef2C

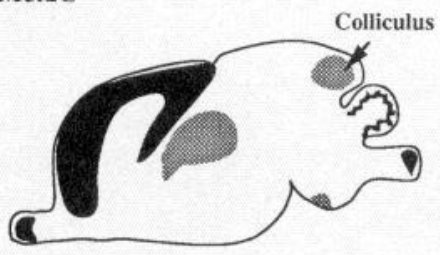

Mef2B

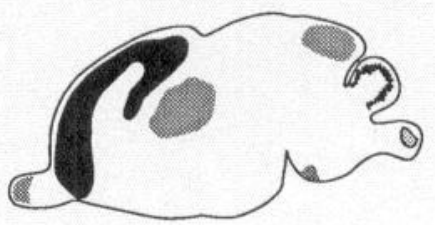

Mef2D

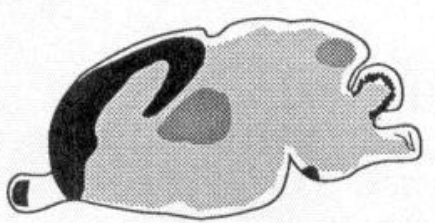

Figure 5. Schematic representation of $M e f 2$ gene expression in the 14.5 d p.c. and neonatal mouse brain. The regions of gene expression are indicated as shaded areas. The intensity of hybridization signal is indicated by the density of the shading. onic frontal cortex, hippocampus, amygdala, midbrain (Fig. $1 E, F)$, and olfactory bulb (data not shown). In the cerebellar primordium, $\operatorname{Mef} 2 \mathrm{D}$ gene transcripts were localized in the external granule cell layer, a proliferating cell population (see Discussion), whereas $M e f 2 C$ mRNAs appeared to be in the layer of Purkinje cells that underwent their final mitoses at $12-13 \mathrm{~d}$ p.c. (Miale and Sidman, 1961). Mef2B gene transcripts were abundant in the frontal cortex layers, were present at lower levels in the developing hippocampus, amygdala, and midbrain, but were not detectable in the cerebellum (data not shown). Hybridization of serial sections with sense control probes revealed background level of signal with the cRNA probes used (data not shown). Expression patterns of the $M e f 2$ genes at 14.5 d p.c. are summarized in Figure 5.

Transverse and frontal (coronal) sections of embryos were hybridized with each of the four antisense cRNA probes to gain a three-dimensional picture of Mef 2 gene expression. At 15.5-
16.5 d p.c., $M e f 2 A$ mRNA levels above background were found predominantly in cells of the thalamus (Fig. $2 A, G$ ). Mef $2 C$ gene transcripts were detected at high levels in several cell layers of the olfactory bulbs and parietal cortex and at lower levels in the developing cerebellum (Fig. $2 C, F, H$ ). Mef $2 B$ gene transcripts (Fig. $2 B, E$ ) were also present in the parietal cortex neurons, but were much more restricted in their distribution than $M e f 2 C$ mRNAs. $M e f 2 D$ gene transcripts overlapped with those of $M e f 2 C$, but were present at lower levels (Fig. 2D).

At $16.5 \mathrm{~d}$, low levels of $M e f 2 A$ mRNAs overlapped with higher levels of $M e f 2 C$ in the hippocampus (Fig. 3A,C), midbrain, and frontal cortex. $M e f 2 B$ gene transcripts were also detected in both the frontal and midbrain cortex layers II-VI with $\mathrm{Mef} 2 \mathrm{C}$ mRNAs (Fig. $3 B, C$ ) at 16.5 d p.c. Mef $2 D$ (Fig. $3 D$ ) was the most widely expressed of the four genes in the brain, which was consistent with its pattern of expression in the other embryonic tissues (Edmondson et al., 1994). Mef2D transcript levels were 

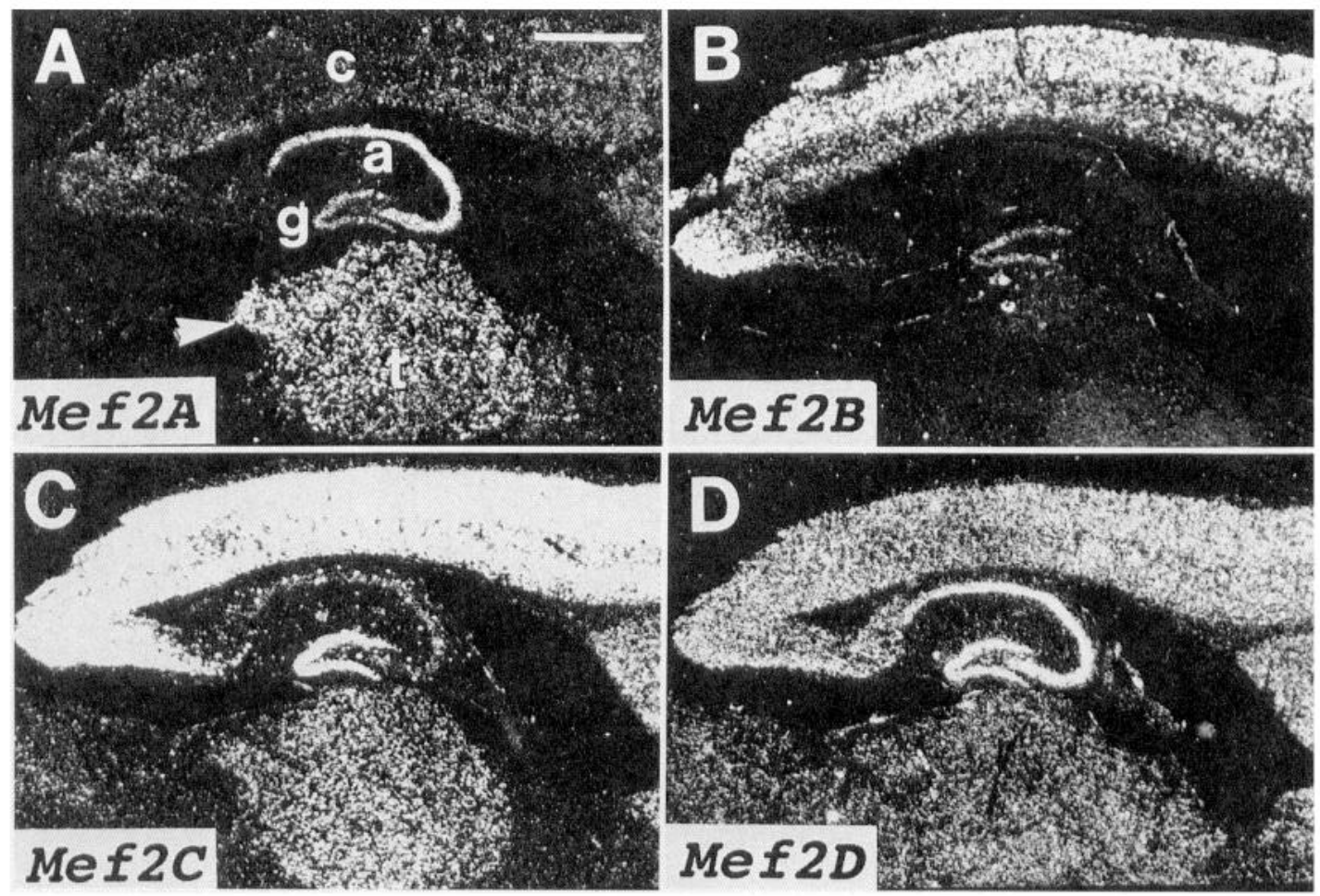

Figure 6. Spatial patterns of Mef2 gene expression in 2 week postnatal brain. Parasagittal sections were hybridized to probes for $M e f 2 A(A),-B$ $(B),-C(C)$, and $-D(D)$. Arrowhead points to the lateral geniculate nucleus in the thalamus $(t)$. $c$, cerebral cortex; $a$, horn of Ammon; $g$, dentate gyrus. Scale bar, $800 \mu \mathrm{m}$.

generally lower than those of the other Mef2 genes. Mef $2 \mathrm{~A}$ gene transcript levels were highest in the thalamus but were also found in the region of the pontine nuclei and the frontal cortex (Fig. 3A).

\section{Postnatal ${ }^{\mathrm{N} \sim 2} 2$ gene expression in the brain}

At birth, the expression patterns of $M e f 2 B$ and $M e f 2 C$ mRNAs overlapped in frontal cortex layers II to VI and in the olfactory bulbs, but the hybridization signal with the $M e f 2 C$ probe was higher in the more internal layers, V and VI (Fig. $4 A-D$ ). Both of these genes were expressed in the pontine nuclei and medulla oblongata (Fig. $4 E$ ). The level of expression varied for these two genes within regions of the thalamus (data not shown). At this stage, signal in the inferior colliculus was clearly defined (Fig. $4 E$ ). This was the first time that $M e f 2 B$ gene transcripts were detectable in the cerebellum. Both $M e f 2 B$ and $M e f 2 C$ mRNAs were localized in a layer deep to the external granule layer (Fig. $4 \mathrm{~F}-\mathrm{H}$; Altman and Bayer, 1995), which likely consists of a mixture of Purkinje cells and differentiated granule cell neurons. Expression patterns of the Mef 2 genes in the neonatal brain are summarized in Figure 5.

In the 2 week postnatal brain, each of the four $M e f 2$ genes were expressed in the dentate gyrus (Fig. 6). Mef $2 C$ and $M e f 2 D$ mRNAs were present at higher levels than were those of $M e f 2 A$ and $M e f 2 B$. Mef $2 C$ gene transcripts were detected in a subset of pyramidal cells in the horn of Ammon of the hippocampus (Fig. $6 C$ ), but $M e f 2 B$ mRNAs were not present in any cells of this structure (Fig. 6B). Mef $2 A$ (Fig. 6A) and $M e f 2 D$ (Fig. 6D) were expressed at similar levels in neurons of the horn of Ammon, but $M e f 2 D$ levels were higher than those of $M e f 2 A$ in the dentate gyrus cells. $M e f 2 C$ and $-D$ genes were expressed equally throughout the layers of the frontal cortex, but Mef $2 C$ mRNAs were more abundant. Mef $2 A$ mRNA levels were slightly above background in the cerebral cortex (Fig. 6A), while Mef $2 B$ gene transcripts were present at higher levels in the outer half of the cortical neuron layers (Fig. $6 B$ ). Mef $2 A$ mRNAs appeared to be slightly more abundant in the lateral geniculate nucleus than those of $M e f 2 C$ and $-D$, while $M e f 2 B$ mRNAs were not detectable in this structure. The $M e f 2 C$ gene transcripts were at slightly higher levels in the thalamus than those of $M e f 2 A$ and $-D$, while $M e f 2 B$ gene transcripts were also undetectable in these neurons.

Between 2 and 6 weeks after birth, changes occurred in the expression patterns of Mef 2 genes in the brain. The most striking pattern of Mef 2 gene expression was in the mature cerebellum. $M e f 2 A$ gene transcripts were detected at low levels in all cerebellar cells, but slightly higher levels occurred in the granule cell layer (Fig. 7G,L). Mef $2 B$ mRNAs were undetectable in the cerebellum (Fig. $7 H, M$; folds in the white matter at the center of $H$ and $M$ appear refractile in dark-field illumination and do not represent positive signal). $M e f 2 C$ gene transcripts were detected at high levels in the cell bodies but were below detectable levels in the dendrites of Purkinje cells (Fig. 7I,N). Mef2C mRNAs were detected as a series of parasagittally oriented stripes (data not shown), as indicated by the comparison of a series of parasagittal sections hybridized to this probe. Mef $2 D$ mRNAs were found predominantly in the granule cell layer of the cerebellum (Fig. 7J,O). Since the autoradiographic grains were detected in the emulsion overlying the embryo or postnatal brain sections, the in situ data presented here do not permit assignment of $\mathrm{Mef} 2$ gene expression to individual neurons or supporting glia. However, the striking localization of $\mathrm{Mef} 2 \mathrm{C}$ hybridization signal over Purkinje cells and large neurons in the 

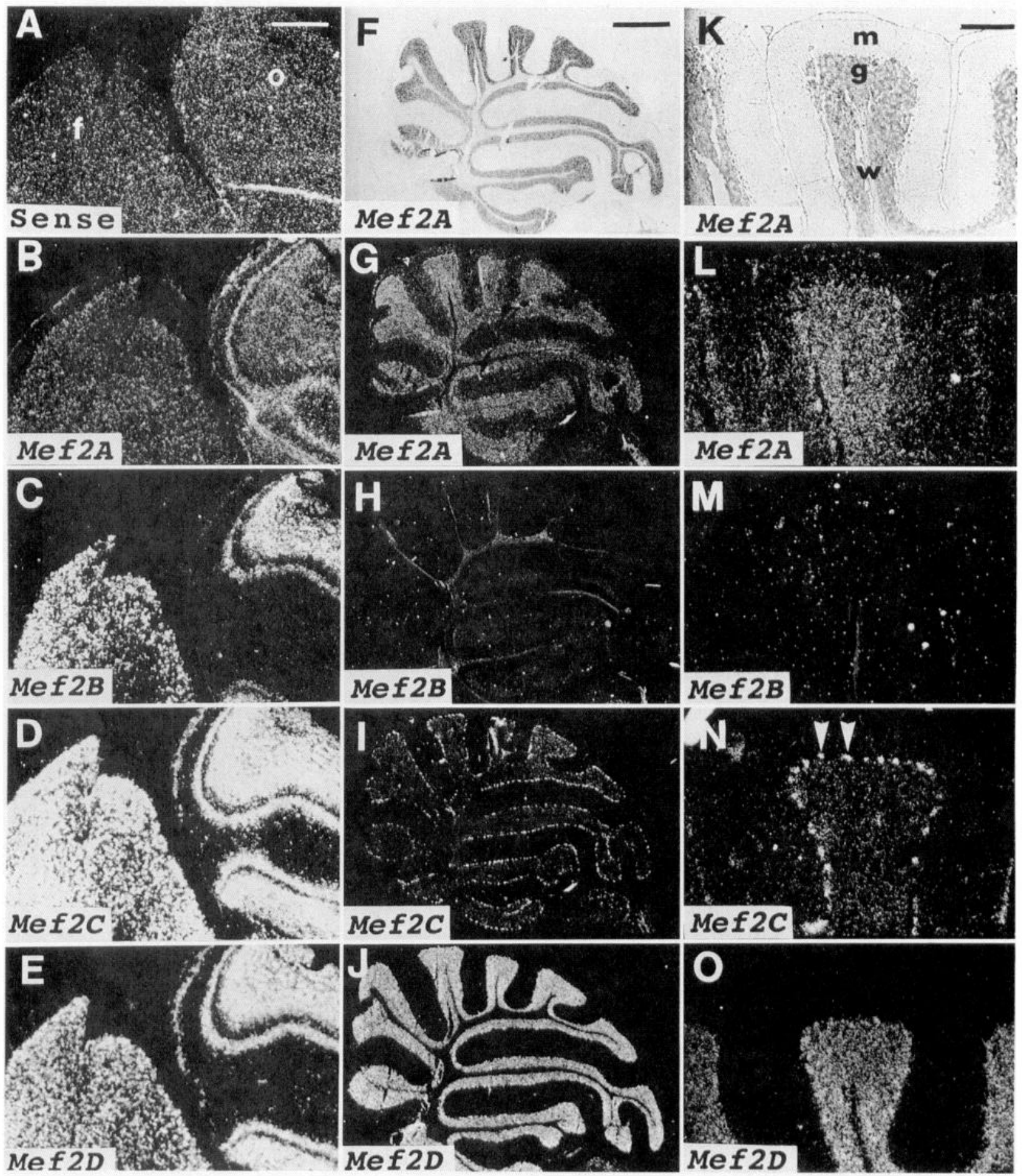

Figure 7. Mef2 gene transcripts are localized in overlapping but distinct regions in the adult (6 week postnatal) mouse brain. $A-E$, Parasagittal sections through the olfactory bulb and frontal cortex were hybridized to probes for Mef $2 A$ sense control $(A), M e f 2 A(B),-B(C),-C(D)$, and $-D$ (E). $F-J$, Parasagittal sections through the cerebellum were hybridized with probes for bright-field $(F), M e f 2 A(G),-B(H),-C(I)$, and $-D(J)$. The sections in $F-J$ are enlarged in micrographs $K-O$ to illustrate the layer-specific expression of $M e f 2$ genes in the cerebellum. Sections were hybridized with probes to bright-field $(K), \operatorname{Mef2A}(L),-B(M),-C(N)$, and $-D(O)$. Arrowheads in $N$ point to Purkinje cells. $g$, inner granule cell layer; $m$, molecular layer; $w$, white matter. Scale bars: $A-E, 600 \mu \mathrm{m} ; F-J, 800 \mu \mathrm{m} ; K-O, 200 \mu \mathrm{m}$.

hippocampus strongly suggest that Mef2 genes are only being expressed in neurons in the CNS.

The patterns of overlapping expression in the dentate gyrus, hippocampus (data not shown), olfactory bulbs, and frontal cortex (Figs. 6,7) remained similar if not identical to that seen at
2 weeks. Throughout the adult brain $M e f 2 D$ mRNAs were most widely expressed, and $M e f 2 B$ gene transcripts were most restricted (data not shown). Expression patterns of the Mef2 genes in the embryonic and postnatal mouse brain are summarized in Figures 5 and 8 and in Table 1. 


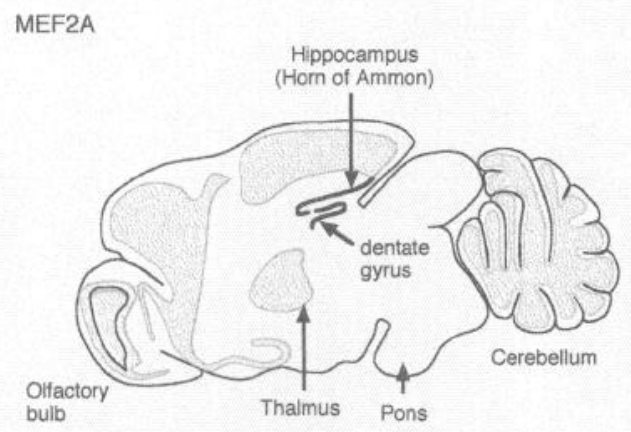

MEF2B
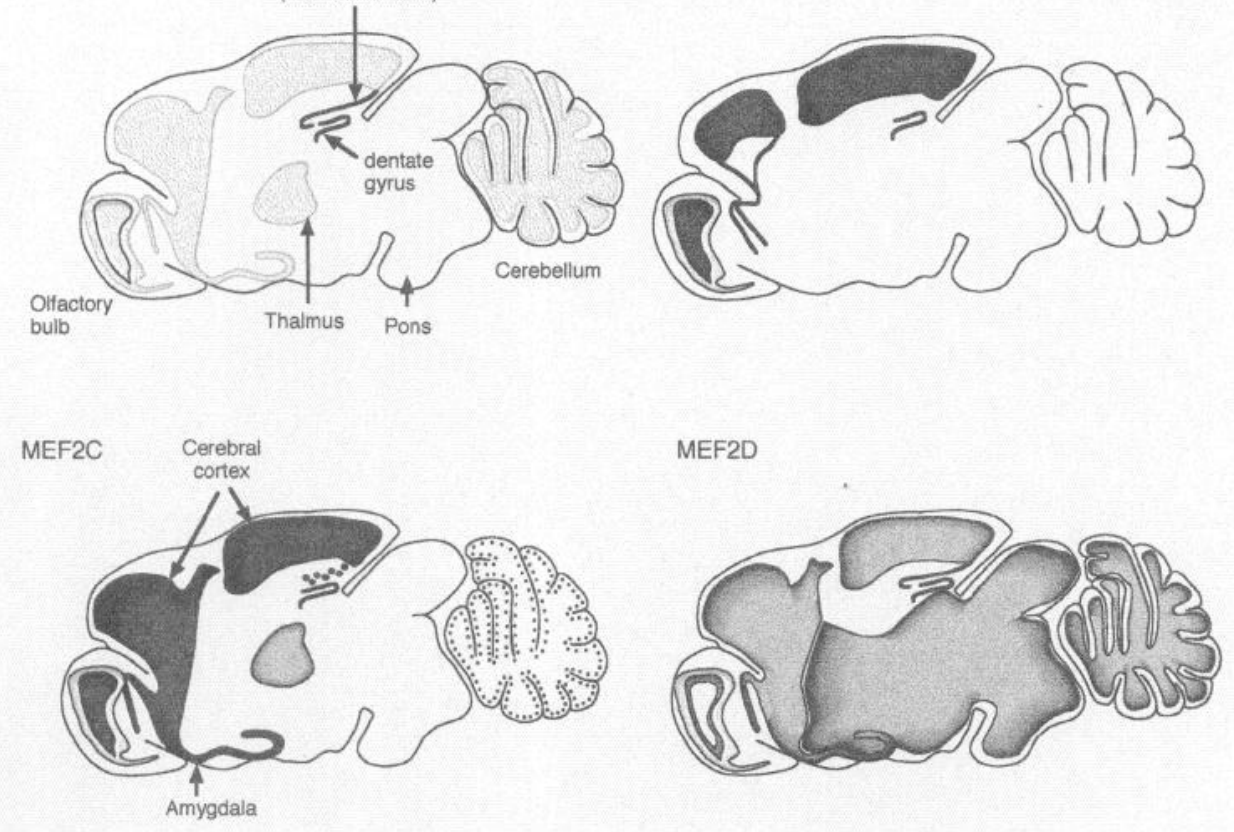

Figure 8. Schematic representation of Mef2 gene expression in the adult mouse brain. The regions of gene expression are indicated as shaded areas. The intensity of hybridization signal is indicated by the density of the shading.

\section{Discussion}

Our results demonstrate that members of the Mef2 gene family are expressed in a dynamic pattern during pre- and postnatal development of the mouse CNS. Other multigene families of transcription factors that have been described in the developing CNS such as the Pax genes (Stoykova and Gruss, 1994) and the Otx genes (Frantz et al., 1994) appear to be involved in brain segmentation and regionalization. The Mef2 genes appear to be associated with withdrawal of neurons from the cell cycle and expression of a differentiated phenotype. Each of the Mef2 genes showed distinct, but often overlapping patterns of expression in different regions of the brain, which suggests that they may perform unique roles at different stages of neuronal maturation. The overlapping expression patterns of the Mef 2 genes in the developing brain are reminiscent of the expression of these genes in developing myogenic cell lineages, in which they have been implicated in the control of muscle-specific gene expression (Edmondson et al., 1994).

There are several interesting parallels between differentiation of muscle cells and neurons. Both cell types are electrically excitable and become postmitotic prior to differentiation, which suggests that some genes in these two cell types may be regulated by common sets of transcription factors. The recent findings of expression of the myogenic regulatory gene, myf-5, in certain regions of the embryonic brain and in myogenic cells derived from the mouse neural tube supports this hypothesis (Buckingham and Tajbakhsh, 1993; Tajbakhsh et al., 1994). The differentiation of several neuronal cell types in Drosophila and mammals has also been shown to be controlled by networks of bHLH factors similar to those in the skeletal muscle lineage (Jan and Jan, 1993). In light of the fact that MEF2 factors and myogenic bHLH proteins regulate one another's expression in skeletal muscle cells and cooperate to induce skeletal muscle gene expression (Cserjesi and Olson, 1991; Lassar et al., 1991; Kaushal et al., 1994), it is tempting to speculate that neuronal differentiation may also involve interactions between neurogenic bHLH proteins and MEF2 factors.

\section{Mef 2 expression in the cerebellum}

The correlation of expression patterns of the Mef 2 genes with morphogenetic events and neuron differentiation in the cerebellum was particularly striking. The cerebellum appears at 10 to $12 \mathrm{~d}$ p.c. as an evaginated thickening in the anterior part of the fourth ventricle. After extensive cell division and migration, a substantial cerebellar plate has formed by 14 d p.c. The plate contains a primitive ependymal zone with a granular layer in its outer region, a thin molecular layer, and an external granule cell layer (Miale and Sidman, 1961).

Precursors of Purkinje cells undergo their final mitotic divisions between 11 and $13 \mathrm{~d}$ p.c., which is the first stage at which we detect $M e f 2 C$ mRNAs in the cerebellum. These neurons migrate distally, and by $17 \mathrm{~d}$ p.c. are located in the primordium of the granule layer of the cerebellar cortex deep to the molecular layer (Miale and Sidman, 1961). Our results with Mef2C gene expression in the $16 \mathrm{~d}$ p.c. and neonatal cerebellum correlate well with this pattern. Although Purkinje cells form early, they do not become distinctly larger than neighboring cells until after birth, and are not arranged in a characteristic single layer until approximately $10 \mathrm{~d}$ after birth (Miale and Sidman, 1961). As they do so, it is clear that only $M e f 2 C$ mRNAs are detected in these large cerebellar neurons.

$M e f 2 D$ gene expression is first detected in the most distal portion of the developing cerebellum at $14.5 \mathrm{~d}$ p.c. These cells may represent the external granule cell layer (EGL), which originates within the rhombic lip of the cerebellum and which gives rise to the granule cell neurons (reviewed in Hatten, 1993). Since the EGL is a zone of cell proliferation, our data suggests that $M e f 2 D$ gene transcripts can be expressed in cells that are still dividing. The granule cell precursors in the EGL later become postmitotic and begin to differentiate postnatally within the sub- 
Table 1. Relative levels of Mef2 gene expression in developing brain

\begin{tabular}{|c|c|c|c|c|c|c|c|}
\hline & & Days & coitum & & & & \\
\hline & & 12.5 & 14.5 & 16.5 & $\mathrm{Nn}$ & 2 week & Adult \\
\hline Olfactory bulb & $2 \mathrm{~A}$ & - &.+ & + & + & + & + \\
\hline & $2 \mathrm{~B}$ & - & + & + & ++ & ++ & +++ \\
\hline & $2 \mathrm{C}$ & - & ++ & ++ & +++ & +++ & +++ \\
\hline & $2 \mathrm{D}$ & + & 11 & ++ & ++ & ++ & ++ \\
\hline Amygdala & $2 \mathrm{~A}$ & - & - & - & - & + & + \\
\hline & $2 B$ & - & - & $+1-$ & - & - & - \\
\hline & $2 \mathrm{C}$ & + & +++ & +++ & + & - & ++ \\
\hline & $2 \mathrm{D}$ & $+1-$ & ++ & ++ & + & + & ++ \\
\hline Cerebral cortex & $2 \mathrm{~A}$ & - & - & + & + & + & + \\
\hline & $2 \mathrm{~B}$ & + & ++ & ++ & +++ & ++ & $+t+$ \\
\hline & $2 \mathrm{C}$ & ++ & +++ & +++ & +++ & +++ & +++ \\
\hline & $2 \mathrm{D}$ & + & + & ++ & ++ & ++ & ++ \\
\hline Hippocampus & $2 \mathrm{~A}$ & nd & - & - & + & +++ & +++ \\
\hline & $2 B$ & nd & + & + & + & + & $+I-$ \\
\hline & $2 \mathrm{C}$ & nd & +++ & +++ & ++ & ++ & ++ \\
\hline & $2 \mathrm{D}$ & nd & + & + & + & +++ & +++ \\
\hline Thalamus & $2 \mathrm{~A}$ & ++ & ++ & +++ & +++ & +++ & +++ \\
\hline & $2 \mathrm{~B}$ & - & + & + & + & ++ & - \\
\hline & $2 \mathrm{C}$ & + & + & + & + & + & ++ \\
\hline & $2 \mathrm{D}$ & 1 & $t$ & + & ++ & + & ++ \\
\hline Midbrain/colliculus & $2 \mathrm{~A}$ & - & + & + & + & + & - \\
\hline & $2 \mathrm{~B}$ & - & - & - & + & ++ & ++ \\
\hline & $2 \mathrm{C}$ & - & ++ & ++ & ++ & ++ & +++ \\
\hline & $2 \mathrm{D}$ & - & ++ & ++ & ++ & ++ & ++ \\
\hline Cerebellum & $2 \mathrm{~A}$ & nd & - & - & + & + & + \\
\hline & $2 \mathrm{~B}$ & nd & - & - & ++ & + & - \\
\hline & $2 \mathrm{C}$ & nd & + & ++ & ++ & $+t$ & + \\
\hline & $2 \mathrm{D}$ & nd & + & + & + & ++ & ++ \\
\hline Pontine nuclei & $2 \mathrm{~A}$ & nd & nd & ++ & ++ & - & + \\
\hline & $2 B$ & nd & nd & $+1-$ & + & ++ & ++ \\
\hline & $2 \mathrm{C}$ & nd & nd & ++ & ++ & ++ & +++ \\
\hline - & $2 \mathrm{D}$ & nd & nd & + & + & + & ++ \\
\hline Medulla & $2 \mathrm{~A}$ & $+1-$ & + & + & + & nd & nd \\
\hline & $2 \mathrm{~B}$ & - & - & + & + & nd & nd \\
\hline & $2 \mathrm{C}$ & - & + & + & + & nd & nd \\
\hline & $2 \mathrm{D}$ & + & + & + & + & nd & nd \\
\hline
\end{tabular}

nd, not determined; Nn, neonatal.

EGL. These neurons migrate inward to form the inner granule cell layer of the mature cerebellum (reviewed in Hallen, 1993). That $M e f 2 D$ gene transcripts continue to be expressed in the inner granule cell layer suggests an important role for this gene in both dividing and postmitotic neuron development.

All four Mef2 genes are detected in a cell layer that lies deep to the EGL at birth. These neurons are likely to be a mixture of Purkinje cells and differentiated granule cells. Mef $2 A$, like $M e f 2 D$, continues to be expressed in the granule cells in the adult, but $M e f 2 B$ gene transcripts decrease to below the level of detection of the in situ hybridization technique. $M c f 2 C$ is expressed exclusively in Purkinje cells in the adult. $M e f 2 A$ and $-B$ expressing cells in the early postnatal cerebellum may represent granule cell neurons that undergo their final mitoses from the late embryo to postnatal day 15 (Miale and Sidman, 1961).

Mef2 gene expression in the hippocampus

In the mouse embryo, the earliest neurons to differentiate in the hippocampus and dentate gyrus undergo their final divisions by
$11 \mathrm{~d}$ p.c. The rate of hippocampal neuron production increases in the next $24 \mathrm{hr}$ to reach a plateau that continues from 12 to $16 \mathrm{~d}$ p.c. The pace then decreases, and only an occasional cell is generated as late as $18 \mathrm{~d}$ p.c. Neurons continue to form in the dentate gyrus until the third postnatal week (Caviness, 1974). In rats, most of the granule cells of the dentate gyrus form postnatally, and hippocampal neurogenesis continues at a low rate until at least 8 months of age (Altman and Das, 1965).

Although we did not detect Mef2 mRNAs in hippocampal cells as early as $12.5 \mathrm{~d}$ p.c., the pattern of $\mathrm{Mef} 2$ gene expression still has a good correlation with the main times of neuron differentiation in this region of the brain as described above. Interestingly, the Mef2 gene transcripts showed overlapping expression at prenatal stages but postnatally, the patterns of the four genes, particularly in the Horn of Ammon cells, were distinct. The lack of expression of $M e f 2 B$ mRNAs and the punctate expression pattern of $M e f 2 C$ gene transcripts suggests that these genes are either downregulated in certain groups of neurons or 
that some neurons in the hippocampus undergo programmed cell death.

\section{Mef2 gene expression in the cerebral cortex}

$M e f 2 C$ is the first gene transcript we were able to detect in the developing cerebrum, and its expression level remained high until 6 weeks after birth. Mef $2 C$ expression was first detected in the intermediate zone of the frontal cortex at day 12.5 p.c. Neurons in this zone underwent mitosis in the subependymal layer of the cortex and migrated into the mantle layer of the cerebral cortex as differentiated cells (Smart, 1961). As devclopment proceeds, neurons continue to migrate into the cortex to form six distinct layers. This is reflected in the gradual increase in thickness of the cortical layers positive for $M e f 2 C$ gene expression. $M e f 2 B$ mRNAs were detected predominantly in the six cortical layers of neurons, whereas $M e f 2 C$ was expressed in both the cortical layers and deep gray matter (Smart, 1961).

Expression of $M e f 2 C$ in the cortex was also observed in a preliminary study in which a human $M e f 2 C$ cDNA was used to analyze expression in tissue sections of rat brain (Leifer et al., 1993). However, in contrast to our results, they reported that $M e f 2 C$ mRNA levels decreased between 1 and 4 weeks after birth in the rat cerebral cortex. The contrasting results for $M e f 2 C$ gene expression patterns between the two studies may be due to species differences in the $M e f 2 C$ gene between rat and mouse or rat and human, or to differences in the hybridization protocols used.

\section{Mef2 gene expression in the thalamus}

In the embryo, the expression of $M e f 2 A$ in the thalamus was striking. Neurons of the ventral thalamus begin to differentiate as early as $10 \mathrm{~d}$ p.c., but cells in different nuclei within this area continue to arise through $16 \mathrm{~d}$ p.c. A lateromedial or "outsidein" gradient in the time of neuron origin is seen in the clorsal thalamus and epithalamus (Angevine, 1970). Examination of coronal and transverse sections at $15-16 \mathrm{~d}$ p.c. hybridized with the $M e f 2 A$ probe reveal a greater number of grains over the lateral neurons of the thalamus compared to the medial cells. A second caudorostral gradient of neuron origin occurs in the dorsal thalamus (Angevine, 1970). A parasagittal section of a $16 \mathrm{~d}$ p.c. mouse brain hybridized with the $M e f 2 A$ probe shows a higher density of silver grains over the caudal portion of the thalamus compared to the adjacent rostral region. Overall, these data suggest that $M e f 2 A$ may play an important role in the prenatal differentiation of thalamic neurons.

\section{Mef2 factors may collaborate with bHLH proteins to induce cell-specific transcription}

In light of the restricted expression of $M e f 2$ genes to early myogenic and neurogenic lineages, it is tempting to speculate that members of the MEF2 family are involved in activating the specific programs of gene expression associated with these lineages. How might these factors participate in these different developmental programs? We favor the hypothesis that the actions of MEF2 proteins are influenced by other factors unique to different cell lineages. Accordingly, within mesodermal cell types, MEF2 proteins activate muscle gene expression, whereas in ectodermal derivatives they activate neural gene expression. In this regard, it is well established that the actions of MADS proteins are influenced by other regulatory factors with which they interact. Thus, muscle and neuronal precursors may express different cofactors for MEF2 activity that help determine which potential target genes are activated. That MEF2 proteins collaborate with myogenic bHLH proteins to regulate skeletal muscle gene expression raises the possibility that neural bHLH proteins, such as the MASH gene products (Lo et al., 1991) or the ME1 gene product (Neuman et al., 1993), may act in conjunction with MEF2 proteins to regulate neural genes.

The expression of $M e f 2$ genes in the myogenic and neurogenic lineages raises interesting questions about the cis- and trans-regulatory systems that activate these genes in different cell types. Analysis of the control regions of the Mef 2 genes will undoubtedly yield insight into the mechanisms that specify the myogenic and neurogenic programs for cell-specific gene expression during development

\section{References}

Altman J, Bayer SA (1995) Atlas of prenatal rat brain development Ann Arbor, MI: CRC.

Altman J, Das GD (1965) Autoradiographic and histological evidence of postnatal hippocampal neurogenesis in rats. J Comp Neurol 124: 319-336.

Angevine JB (1970) Time of neuron origin in the diencephalon of the mouse. An autoradiographic study. J Comp Neurol 139:129-188.

Breitbart R, Liang C, Smoot L, Laheru D, Mahdavi V, Nadal-Ginard B (1993) A fourth human MEF-2 transcription factor, hMEF2D, is an early marker of the myogenic lineage. Development 118:1095-1106.

Buckingham ME, Tajbakhsh S (1993) Expression of the myogenic factors in the mouse: myf-5, the first member of the $M y o D$ gene family to be transcribed during skeletal myogenesis. C R Acad Sci III 316 : 1040-1046.

Caviness VS (1974) Time of neuron origin in the hippocampus and dentate gyrus of normal and reeler mutant mice: an autoradiographic study. J Comp Neurol 151:113-120.

Chambers A, Kotecha S, Towers N, Mohun T (1992) Muscle-specific expression of SRF-related genes in the early embryo of Xenopus laevis. EMBO J 11:1-4991.

Cheng TC, Wallace M, Merlie J, Olson E (1993) Separable regulatory elements govern myogenin transcription in embryonic somites and limbbuds. Science 261:215-218.

Cserjesi P, Olson E (1991) Myogenin induces muscle-specific enhancer binding factor MEF-2 independently of other muscle-specific gene products. Mol Cell Biol 11:4854-4862.

Edmondson D, Cheng T, Cserjesi P, Chakraborty T, Olson E (1992) Analysis of the myogenin promoter reveals an indirect pathway for positive autoregulation mediated by MEF2. Mol Cell Biol 12:36653677.

Edmondson DG, Lyons GE, Martin J, Olson E (1994) Mef2 gene expression marks the cardiac and skeletal muscle lineages during mouse embryogenesis. Development 120:1251-1263.

Frantz GD, Weimann JM, Levin ME, Mcconnell SK (1994) OtxI and $O t \times 2$ define layers and regions in the developing cerebral cortex and cerebellum. J Neurosci 14:5725-5740.

Gossett L, Kelvin D, Sternberg E, Olson E (1989) A new myocytespecific enhancer binding factor that recognizes a conserved element associated with multiple muscle specific genes. Mol Cell Biol 9:5022-5033.

Hatten ME (1993) The role of migration in central nervous system neuronal development. Curr Opin Neurobiol 3:38-44.

Jan YN, Jan LY (1993) HLH proteins, fly neurogenesis, and vertebrate myogenesis. Cell 75:827-830.

Kaufman MH (1992) The atlas of mouse development. New York: Academic.

Kaushal S, Schneider JW, Nadal-Ginard B, Mahdavi V (1994) Activation of the myogenic lineage by MEF2A, a factor that induces and cooperates with MyoD. Science 266:1236-1240.

Lassar AB, Davis RL, Wright WE, Kadesch T, Murre C, Voronova A, Baltimore D, Weintraub H (1991) Functional activity of myogenic HLH proteins requires hetero-oligomerization with E12/E47-like proteins in vivo. Cell 66:305-315.

Leibham D, Wong M, Cheng T, Schroeder S, Weil P, Olson E, Perry M (1994) Binding of TFIID and MEF2 to the TATA element activate transcription of the Xenopus MyoDa promoter. Mol Cell Biol 14:686699. 
Leifer D, Krainc D, Yu Y, McDermott J, Breitbart R, Heng J, Neve R, Kosofsky B, Nadal-Ginard B, Lipton S (1993) MEF2C, a MADS/ MEF-2 family transcription factor expressed in a laminar distribution in cerebral cortex. Proc Natl Acad Sci USA 90:1546-1550.

Lo L, Johnson J, Wuenschell C, Saito T, Anderson D (1991) Mammalian achaete-scute homolog 1 is transiently expressed by spatially restricted subsets of early neuroepithelial and neural crest cells. Genes Dev 5:1524-1537.

Lyons GE, Ontell M, Cox R, Buckingham M (1990) The expression of myosin genes in developing skeletal muscle in the mouse embryo. J Cell Biol 111:1465-1476.

Martin J, Schwartz J, Olson E (1993) MEF2C: a tissue-restricted member of the MEF2 family of transcription factors. Proc Natl Acad Sci USA 90:5282-5286.

Martin J, Miano J, Hustad C, Copeland N, Jenkins N, Olson E (1994) A $M e f 2$ gene that generates a muscle-specific isoform via alternative mRNA splicing. Mol Cell Biol 14:1647-1656.

McDermott J, Cardoso M, Yu Y, Andres V, Leifer D, Krainc D, Lipton S, Nadal-Ginard B (1993) hMEF2C gene encodes skeletal muscleand brain-specific transcription factors. Mol Cell Biol 13:2564-2577.

Miale I, Sidman R (1961) An autoradiographic analysis of histo-genesis in the mouse cerebellum. Exp Neurol 4:277-296.

Navankasattusas S, Zhu H, Garcia A, Evans S, Chien K (1992) A ubiquitous factor (HF-1) and a distinct muscle factor (HB-1b/MEF2) form an E-box-independent pathway for cardiac muscle gene expression. Mol Cell Biol 12:1469-1479.
Neuman T, Keen A, Knapik E, Shain D, Ross M, Nornes H, Zuber M (1993) ME1 and GE1: basic helix-loop-hclix transcription factors expressed at high levels in the developing nervous system and in morphogenetically active regions. Eur J Neurosci 5:311-318.

Pollock R, Treisman R (1992) Human SRF-related proteins: DNAbinding properties and potential regulatory targets. Genes Dev $5: 2327-2341$.

Rugh K (1990) 'The mouse: its reproduction and development. Oxford: Oxford UP.

Schambra UB, Lauder M, Silver J (1992) Atlas of the prenatal mouse brain. New York: Academic.

Smart I (1961) The subependymal layer of the mouse brain and cell production as shown by autoradiography after thymidine- $\mathrm{H}^{3}$ injection. J Comp Neurol 116:325-347.

Stoykova A, Gruss P (1994) Roles of Pax-genes in developing and adult brain as suggested by expression patterns. J Neurosci 14:13951412.

Tajabakhsh S, Vivarelli E, Cusella-DeAngelis G, Rocancourt D, Buckingham $M$, Cossu $G$ (1994) A population of myogenic cells derived from the mouse neural tube. Neuron 13:813-821.

Yee S, Rigby P (1993) The regulation of myogenin gene expression during the cmbryonic development of the mouse. Genes Dev 7:12771289.

Yu Y, Breitbart R, Smoot L, Lee Y, Mahdavi V, Nadal-Ginard B (1992) Human myocyle specific enhancer factor 2 (MEF2) comprises a group of tissue restricted MADS box transcription factors. Genes Dev 6:1783-1798. 